\title{
Faculty Teaching Partners and Associates: Engaging Faculty as Leaders in Instructional Development
}

\author{
Myra S. Wilhite \\ Joyce Povlacs Lunde \\ Gail F. Latta \\ University of Nebraska, Lincoln
}

Special interest discussion groups provide opportunities for faculty to address specific instructional issues in a variety of areas including tecbnology, distance learming, general teaching topics, pre-tenure issues, bonors teaching, and the like. In 1995, to leverage the Teaching and Learning Center's resources, outstanding classroom leachers were invited to provide leadership for discussion groups by serving as Partners or Associates. This chapter describes how an inexpensive faculty discussion-group leadership program maximizes a teaching improvement center's resources, makes innovative teaching visible, and provides peer models for other faculty while belping promote an overall institutional culture that actively supports teaching excellence.

Tndividualized instructional consulting is a major tool of teaching Iimprovement centers, as numerous handbooks and resources for practitioners demonstrate (e.g., Lewis \& Povlacs, 1988; Wadsworth, 1988; Brinko \& Menges, 1997). Its effectiveness has been demonstrated by empirical studies (Cohen, 1980; Menges \& Brinko, 1986). However, as most faculty developers know, one-to-one individualized consultation is labor-intensive, especially if it moves through the four phases of initial contact, conference, information collection, and information review and planning (Brinko, 1997). In the face of budget constraints, re-allocations, 
demands for assessment, post-tenure review, and the like, faculty developers in teaching improvement centers must look for ways to expand the impact of their work, without resorting to superficial solutions.

The purpose of this paper is to describe how an inexpensive faculty discussion-group leadership program leverages a teaching improvement center's resources, makes innovative teaching visible, and provides peer models to other faculty while helping promote an overall institutional culture that actively supports teaching excellence.

\section{FACULTY AS LEADERS IN INSTRUCTIONAL IMPROVEMENT}

\section{TLC Partners}

Over the years the Teaching and Learning Center at the University of Nebraska, Lincoln has asked selected faculty, such as recipients of distinguished teaching awards or former clients with special expertise, to lead workshops. However, when we wanted to offer more faculty an expanded leadership role (e.g., panelists, discussion group leaders, etc.), we had trouble identifying capable and willing faculty. We tried publishing a general call for volunteers in our newsletter and in a special mailing, but the response was discouraging. When we reflected on our inability to attract faculty, we were struck by Boice's words: "When senior faculty are asked why they have not participated in faculty development programs, their answer is nearly uniform: it is because, in their view, no one has asked them in a meaningful way" (Boice, 1992, p. 314). In an effort to find "a more meaningful way" to encourage more faculty to take a leadership role in our programs, we established the TLC Teaching Partner program.

We launched the Partner program in 1995 by sending a flyer to all faculty saluting those who had recently contributed to TLC programming and providing an opportunity for faculty to sign up to become a Teaching Partner. Potential partners were asked to share their teaching expertise, experiences, and insights in our discussion groups and conversation series by serving as panelists or facilitators/presenters. Faculty were asked to indicate topics of interest. The response was very encouraging. Faculty who had never before participated in TLC events (as leaders or participants) volunteered to take a leadership role in instructional development activities. Faculty seemed to appreciate the special recognition of "partnering" with the university's faculty development center and eagerly identified a special interest or particular area of expertise to share 
with colleagues. In the three years prior to the initiation of the Partner/ Associate program, 75 faculty served in leadership roles. By 1997, more than 40 faculty representing 34 academic units were participating each semester.

\section{TLC Associates}

We developed the TLC Associates Program as another means of recruiting faculty to take a leadership role in instructional improvement. These leadership roles usually require special expertise and a more extensive time commitment than partners. In recent years, as campus and faculty needs have changed (e.g., instructional technology, distance education, the Comprehensive Education Program) and Center staff has remained constant, alternatives to in-house expertise were needed to best support faculty in these new areas. The TLC Associates Program was launched in 1994 when, with little additional funding available, we created the position of TLC Associate for Instructional Technology. Center staff lacked experience and expertise in instructional technology. To provide faculty development opportunities in that area, we went outside the Center, naming a faculty member from the teachers college to lead the faculty development effort. With the approval of his college dean and funding from the office of academic affairs, the new TLC Associate took a leadership role in facilitating workshops and discussion groups and in providing individual consulting in instructional technology. Because the TLC Associate was successful in meeting the needs of faculty, we extended his appointment a second year. Since that time, five other faculty members have been invited to serve as Associates: two for the Distance Education Learning Group, one as leader of Let's Talk Teaching (a discussion group for general teaching issues), one for the Comprehensive Education Program (a university-wide general education program), and one replacing the first Associate for Instructional Technology. Most Associates plan and facilitate a monthly discussion group. They may contribute an occasional newsletter article, conduct faculty surveys, form and moderate email special interest groups, collaborate with TLC faculty on workshops and grants, or provide individual consultation in their area of interest.

To prepare faculty for their leadership role, Center instructional consultants establish a close working relationship with Partners and Associates from the planning phase through evaluation and follow up. TLC consultants meet each faculty leader to discuss interests and expertise, explore cffective format, and determine schedules. Consultants attend 
each session and provide follow-up on request. Center staff handle publicity, room reservations, registration, duplicate handouts, and evaluation forms. Leaders receive an evaluation summary of each discussion group session to facilitate ongoing planning. With the help of faculty Partners and Associates, the number of discussion-groups sessions increased from 10 in 1992-93 to more than 80 in 1997-98.

\section{Special InTERest Discussion Groups}

As indicated, Partners and Associates become leaders in special-interest discussion groups. These discussion groups are scheduled to meet over a semester or an academic year. They are organized around specific topics providing faculty an opportunity to become familiar with the literature and to explore instructional issues and strategies around that specific topic. This sustained interaction among colleagues often fosters a sense of community, a collegial environment of exploration, and a safe place for examining one's current teaching practices and exploring alternatives (Jarvis, 1991; Boice, 1992). As a result, special-interest discussion groups can be particularly helpful to faculty who wish to make substantive changes in their teaching.

Because teaching tends to be an isolated activity (Green, 1990), an important benefit of group activities sponsored by a teaching improvement center lies in bringing together faculty from different disciplines and of different ages and ranks. Discovering common interests in a discussion-group setting helps reduce a sense of professional isolation that some faculty members may feel. "It is helpful to know that other faculty members struggle with the same issues and have different insights based on their experiences" (Green, 1990, p. 58), or, as Jarvis puts it, "Professors enjoy the chance to escape their professional boxes and to discuss larger issues" (Jarvis, 1991, p. 61).

Since discussion groups often transcend disciplines in their membership and offer a collegial environment for exploring and improving practice, developing and supporting special-interest discussion groups is a worthy faculty development program objective. They are cost effective, time efficient, and can extend the opportunities a small staff can provide. Discussion groups introduce faculty to theories of effective teaching, model good teaching techniques and strategies, keep teaching at the forefront of academic work, and help promote a culture that actively supports teaching excellence. 
Between 1992 and 1997, the Center sponsored the seven discussion groups listed in Figure 11.1. Seventy-eight sessions were offered (Wright, Banset, Bellows, \& Wilhite, 1997). Figure 11.1 also summarizes information about the purpose of the groups, participation, and the number of discussion-group sessions held. Beginning in 1995, faculty Partners or Associates provided leadership for the groups.

The Century Teaching Club, for teachers of large classes, was one of our first and most popular discussion groups. Dormant for several years in the late 1980s, the group was reestablished in 1992 as more faculty were assigned larger enrollment classes. The group remained active through 1995, when some members began participating in First Tuesday, a technology discussion group. In response to faculty requests, the Center once again organized the group in 1997 under the leadership of a teaching Partner. Historically, members of the Century Teaching Club

\section{FIGURE 11.1}

Special Interest Groups and Faculty Partners/Associates

\begin{tabular}{|l|l|l|c|c|}
\hline Group Name & $\begin{array}{c}\text { Purpose/ } \\
\text { Audience }\end{array}$ & $\begin{array}{c}\text { Partner/ } \\
\text { Associate } \\
\text { Involvement }\end{array}$ & $\begin{array}{c}\text { \# of Mtgs. } \\
\text { Annually }\end{array}$ & $\begin{array}{c}\text { Avg. \# } \\
\text { Participating }\end{array}$ \\
\hline $\begin{array}{l}\text { Century } \\
\text { Teaching Club }\end{array}$ & $\begin{array}{l}\text { for teachers of } \\
\text { large classes }\end{array}$ & facilitator & 6 & 10 \\
\hline $\begin{array}{l}\text { Conversation } \\
\text { Series for Pre- } \\
\text { Tenure Faculty }\end{array}$ & $\begin{array}{l}\text { personal, } \\
\text { professional, and } \\
\text { instructional } \\
\text { development }\end{array}$ & panelists & $4-6$ & 13 \\
\hline First Tuesday & $\begin{array}{l}\text { technology- } \\
\text { novice }\end{array}$ & facilitator & $5-6$ & 37 \\
\hline $\begin{array}{l}\text { Technology } \\
\text { Group }\end{array}$ & $\begin{array}{l}\text { technology- } \\
\text { advanced/ } \\
\text { technical }\end{array}$ & $\begin{array}{l}\text { organizer/ } \\
\text { presenter }\end{array}$ & 9 & 15 \\
\hline $\begin{array}{l}\text { Distance } \\
\text { Education }\end{array}$ & $\begin{array}{l}\text { for faculty teach- } \\
\text { ing on TV or } \\
\text { online }\end{array}$ & facilitators & $4-6$ & 20 \\
\hline $\begin{array}{l}\text { Let's Talk } \\
\text { Teaching }\end{array}$ & $\begin{array}{l}\text { teaching and } \\
\text { leaming issues }\end{array}$ & facilitators & $3-5$ & 21 \\
\hline $\begin{array}{l}\text { Teaching } \\
\text { Matters }\end{array}$ & $\begin{array}{l}\text { teaching topics } \\
\text { for TAs }\end{array}$ & panelists & $2-4$ & 15 \\
\hline
\end{tabular}


have been actively involved in projects that extend beyond monthly meetings: providing opportunities for peer classroom visits for faculty new to large-class teaching, conducting a large lecture hall survey to determine faculty perceptions about physical facilities, sponsoring workshops, and publishing an occasional newsletter. In 1994-95, members of the Club also provided leadership in exploring the use of multimedia in the large class and beyond.

The Conversation Series for Pre-Tenure Faculty (1992-95) provided collegial support for new faculty members: the opportunity to meet with colleagues not only to explore instructional issues, but to examine professional and personal development concerns, especially balance between tasks. Faculty served primarily as panelists at the monthly sessions. New faculty spent time networking over breakfast before exploring personal and professional issues. Participants explored such topics as Balancing Career and Personal Life; Balancing Teaching, Research, and Service; Tips on Testing and Grading; Promoting Discussion in the Classroom; Documenting Effective Teaching for Promotion and Tenure; Classroom Rapport; and Assertiveness: How to Take Charge in a Nice Way. The group met four to six times during the academic year.

The Pre-Tenure Conversation Series was discontinued in 1995 as other issues emerged on campus. To better meet the needs of the general faculty population, the organizer of the Conversation Series initiated two new discussion groups: First Tuesday (technology-related issues) and Let's Talk Teaching (general teaching issues). In addition, the instructional consultant for TAs developed Teaching Matters, a teaching strategies discussion group originally intended for TAs but soon opened to all faculty. The needs of the pre-tenure group were effectively met by these new discussion groups, and during the next two years, TAs and pretenure faculty explored general classroom teaching concerns in the Teaching Matters discussion group (e.g., Organizing and Guiding Group Work; The Teaching Portfolio; Encouraging and Evaluating Student Writing; Classroom Assessment Techniques).

Technology topics accounted for 33 of 78 discussion group sessions between 1992 and 1997. Technology topics seem to draw the largest number of participants, probably because such topics are of current interest to faculty and offer personal as well as professional value. This growing interest among faculty led to the formation in 1995 of First Tuesday, a discussion group focusing on general technology issues in teaching. In addition to First Tuesday, faculty could explore technology issues by participating in the Technology Group. The Technology Group attracted 
mostly "early adopters" and, unlike First Tuesday, focused primarily on the technical aspects of using technology in the classroom. This group was led by the TLC Associate for Instructional Technology, a professor in the teachers college who has been a campus leader in the area of multimedia for classroom use since 1990 and was instrumental in establishing the UNL Teaching, Learning, and Technology Roundtable.

In 1996, a discussion group for Distance Learning faculty was organized on the basis of a needs assessment and interest survey, as well as on the advice of the Distance Learning Advisory Group. In spring 1997, as interest in the UNL Honors Program grew, the TLC formed a new discussion group to provide faculty a forum for exploring issues related to teaching honors students.

\section{ReCOgnition}

It is important to support and recognize the work of discussion group leaders who are the pacesetters for excellence across our campus. Partners and Associates are recognized each year in Teaching at UNL, the Teaching and Learning Center newsletter. Associates' responsibilities usually require special expertise and a more extensive commitment of time than Partners. Associates are given $\$ 1,000$ for professional development in acknowledgment of their contributions. Being recruited and participating in these leadership roles give faculty the sense that they are valued by their colleagues and the institution.

\section{Evaluations of Partners/Associates Programs}

In 1997, we gave our discussion group Partners and Associates the opportunity to provide feedback on the impact their leadership role has had on their own teaching and learning by completing a brief questionnaire (see Appendix 1). In a separate survey, discussion group participants evaluated session effectiveness and identified future topics of interest. All participants who responded to the survey agreed that sessions were well organized, relevant to their professional needs, and gave them new ideas and applications for teaching. Participants also reported increased student involvement in their classes.

\section{Impact on Teaching and Learning}

Although the intrinsic rewards of contributing to the development of colleagues might be reason enough to participate in a leadership role, 
Partners and Associates agreed that their participation as leaders also had a positive impact on their own teaching and learning. When asked to indicate ways in which their leadership role affected their teaching, Partners and Associates reported affirmation of their own efforts, increased self-confidence, increased reflection on teaching, and use of new teaching methods. When asked in what ways they had noticed the effects of these changes beyond their own observations, respondents most often indicated positive comments from faculty and awards and recognition.

As faculty members have become more effective teachers, they have welcomed the opportunity to become partners in instructional development activities and to learn from the expertise and experience of their colleagues, as well as Center and external "experts." One Partner noted: "I've not participated as a leader for recognition, but for my own learning and sense of keeping up with new points of view to see if they agree with my own. Interactions with members of the audience nearly always are profitable." Another faculty leader reflects the sentiments of most: "My participation as a TLC Partner has increased my contacts with others across campus who share interest and expertise in improving the quality of teaching and learning at UNL.... Every year there are things from the Teaching and Learning Center that help me. Presenting is something I do as a payback."

A corollary benefit of faculty leadership is the fact that those who lead sessions tend to draw participants from their own departmentsoften faculty who ordinarily would not attend our activities but come to support or hear their colleagues. One leader noted, "My participation in the Partners/Associates program has heightened awareness of others in my department and college of the importance of innovation in teaching and learning. This is significant!"

\section{Benefits}

Although it takes a considerable amount of TLC staff support and flexibility to coordinate the Partners and Associates program, the overall benefits to faculty across campus, as well as to the leaders, far outweigh the effort required. Originally conceived as a means of extending the ability of Center staff to meet the needs of faculty, the Partners and Associates program has provided additional benefits for Partners, Associates, participants, and the Teaching and Learning Center. The program provides select faculty the opportunity to play a leadership role in instructional development activities, share innovative approaches to teaching, and 
receive feedback from peers in a non-evaluative setting. It is an effective and efficient way for faculty leaders to network with faculty from across campus and collaborate with, and learn from, TLC staff. The program heightens faculty awareness of, and support for, TLC's activities and mission and creates a cadre of faculty who may be tapped to support other TLC functions. In addition, participation results in recognition by colleagues and administrators for service to the academic community, often stimulates faculty development activities within the Associate's own department or college, and provides funding for professional development.

\section{BARRIERS}

Partners and Associates said time was the most difficult obstacle to overcome. Home departments are not likely to provide release time for this activity. Thus, balancing participation in the program with daily demands of teaching, research, and service is problematic. Other potential roadblocks include scheduling, session format, and location.

We have found that a particular day each month works well to keep the date in the minds of faculty. However, a fixed time prevents some faculty from participating because of scheduling conflicts. Although sessions are typically kept short (60-90 minutes) to enable more faculty to work these meetings into their schedules, such time constraints prevent adequate coverage of some topics. For example, this format is not conducive to skills acquisition, only the demonstration and discussion of some possibilities. In addition, there is rarely enough time for Partners or Associates to provide systematic follow up. However, TLC addresses this concern by offering more in-depth activities as follow up to discussion groups as requested.

Technology-based presentations also create unique problems and issues. Media-equipped classrooms are in high demand throughout the day. Because of the limited number of such classrooms, it is always a challenge to find sites that can support these technology-based presentations at a convenient time for faculty.

\section{Conclusion}

Based on our experience at the University of Nebraska, Lincoln, a program that links special issues and priorities across campus with faculty in 
the role of Associates and Partners can achieve significant outcomes. Individual consultation for teaching improvement is important in helping faculty diagnose and improve teaching while a class is in progress; however, it is a time-consuming process that requires considerable skills (Brinko \& Menges, 1997). Although they may not be formally trained in instructional consulting, Teaching Partners and Teaching Associates have their own expertise to offer in targeted areas such as curriculum, technology, or assessment. Faculty Partners and Associates can extend the impact of individual consulting by offering specialized instructional improvement and development services to targeted groups. In following up with individual clients, Teaching Associates can take some of the burden of individual consulting off the shoulders of faculty developers, especially in the area of technology. At the same time, the teaching improvement center offers the service and organizes the development activities. Such a program is cost-efficient and effective, helps the institution achieve goals and priorities in curriculum and instruction, provides professional development opportunities for individual faculty members, breaks down isolation of faculty across disciplines, and improves teaching and learning on a class-by-class basis across the campus.

\section{REFERENCES}

Boice, R. (1992). The newe faculty member. San Francisco, CA: Jossey-Bass.

Brinko, K. T. (1997). The interactions of teaching improvement. In K. Brinko \& R. Menges (Eds.), Practically speaking: A sourcebook for instructional consultants in bigher education (pp. 3-8). Stillwater, OK: New Forums Press.

Brinko, K. T., \& Menges, R. J. (Eds.). (1997). Practically speaking: A sourcebook for instructional consultants in bigher education. Stillwater, OK: New Forums Press.

Cohen, P. A. (1980). Effective use of student-rating feedback for improving college instruction: A meta-analysis of findings. Research in Higher Education, 13 (4), 321-341.

Green, M. F. (1990). Why good teaching needs active leadership. In P. Seldin \& Associates (Eds.), How administrators can improve leaching: Moving from talk to action in higher education (pp. 45-62). San Francisco, CA: Jossey-Bass.

Jarvis, D. K. (1991). Junior faculty development. New York, NY: Modern Language Association of America.

Lewis, K. G., \& Povlacs, J. T. (1988). Face lo face: A sourcebook of individual consul- 
tation teclniques for faculty/instructional developers. Stillwater, OK: New Forums Press.

Lunde, J., \& Wilhite, M. (1996). Innovative teaching and teaching improvement. To Improve the Academy, 15, 155-167.

Menges, R. J., \& Brinko, K. T. (1986, April). Effective use of student coaluation feedback: A meta-analy'sis of bigher education research. Paper presented at the meeting of the America Educational Research Association, San Francisco, CA. (ED 270 408).

Wadsworth, E. C. (Ed.). (1988). A bandbook for new practitioners. Stillwater, OK: Professional \& Organizational Development Network in Higher Education, New Forums Press.

Wilhite, M., Latta, G., \& Lewis, D. (1998, May). A faculty discussion group leadership program: Promoting teaching excellence in a climate of financial austerity. Paper presented at the Faculty College, Mahoney State Park, NE.

Wright, D., Banset, E., Bellows, L., \& Wilhite, M. (1997). Self-study report of the Teaching and Leaming Center prepared for program review. Lincoln, NE: University of Nebraska-Lincoln, Teaching and Learning Center.

Young, R. E., \& Eble, K. E. (1988). College teaching and learning: Preparing for new commitments. New Directions for Teaching and Learning, No. 33. San Francisco, CA: Jossey-Bass.

\section{Contact:}

Myra S. Wilhite

Department of Agricultural Leadership, Education, and Communication 300 Agricultural Hall

University of Nebraska, Lincoln

Lincoln, NE 68583-0709

(402) $472-5991$

(402) $472-5863$ (FAX)

mwilhite@unl.edu

Myra S. Wilhite is an Associate Professor in the Department of Agricultural Leadership, Education, and Communication at the University of Nebraska, Lincoln. She previously served as instructional consultant with the Teaching and Learning Center where she introduced the Partners and Associates program.

Joyce Povlacs Lunde is a Professor Emerita, Department of Agricultural Leadership, Education, and Communication at the University of Nebraska, Lincoln. 
She formerly served as an Educational Development Specialist in the Office of Professional and Organizational Development at UNL.

Gail F. Latta is a Professor in the University Libraries, Teaching and Learning Center Associate for Instructional Technology and Chair of UNL's Teaching, Learning, and Technology Roundtable. 


\section{APPENDIX 11.1 \\ STAFF AND PROGRAM EVALUATION \\ TEACHING AND LEARNING CENTER}

[December, 1997]

Our essential business involves meeting UNL's instructional development needs. You have contributed to this effort by participating in a leadership role in one of our fall semester activities. (List of TLC activities attached.)

Please take a moment to reflect on this experience and provide feedback in two areas:

- Evaluate the TLC staff with whom you interacted in preparation for your leadership role.

- Assess the impact your participation had on your own teaching and learning.

Describe your role: (Check all that apply.)

Facilitator

- Panel Participant

Table Host

Presenter

\section{Part I: Staff Effectiveness}

Indicate your response by using the following scale: $S A=$ Strongly Agree; $A=$ Agree; $N=$ Neither Agree nor Disagree; $D=$ Disagree; $S D=$ Strongly Disagree; $\mathrm{NA}=$ Not Applicable.

TLC staff I worked with:

1. were well organized.

2. were competent and helpful.

3. communicated clear expectations to guide my preparation/ participation in the TLC event.

4. were flexible and open to suggestions.

\section{Part II: Impact on Teaching and Learning}

1. How much has your participation in a leadership role affected your teaching?

$\square$ Very Much

Not Very Much

$\square$ Somewhat

$\square$ Not At All

Not Applicable 
2. In what way(s)? [Mark all that apply]

Increased self-confidence

$\square$ Use of new teaching methods

$\square$ Affirmation of my own efforts

$\square$ Change in course content

$\square$ Change in assignments or exams
Improved teaching methods

$\square$ Better understand learning

$\square$ Increased reflection on teaching

$\square$ Change in course structure

$\square$ Other:

3. Besides your own observations, how have you noticed the effects of these changes?

$\square$ Improved student performance

$\square$ Increased student involvement

$\square$ Improved student ratings

$\square$ Positive comments from faculty

$\square$ Awards and recognition

$\square$ Other:

4. Based on your experience, would you encourage colleagues to take a leadership role in TLC activities?

$\square$ Yes

$\square$ No

5. To what degree do you believe your participation in these activities is valued by your department?

$\square$ Highly valued

$\square$ Minimally valued

$\square$ Moderately valued

$\square$ Negatively valued

\section{Comments:}

Thank you! 